\title{
Clinical evaluation of inline motion correction for cardiac perfusion MRI
}

\author{
Aya Kino ${ }^{1 *}$, Christopher Glielmi², Mauricio S Galizia ${ }^{1}$, Andrada R Popescu', Hui Xue ${ }^{3}$, Jens Guehring Guehring ${ }^{3}$, \\ Peter Weale ${ }^{2}$, Sven Zuehlsdorff', James C Carr ${ }^{1}$
}

From 2011 SCMR/Euro CMR Joint Scientific Sessions

Nice, France. 3-6 February 2011

\section{Objective}

The purpose of this study is to evaluate the impact of non-rigid registration of cardiac perfusion images on image quality and diagnostic accuracy.

\section{Background}

Cardiac MR is often utilized to assess myocardial perfusion [1].Typically, T1 weighted images of the first pass of contrast agent are qualitatively assessed to identify hypo-enhanced regions of the myocardium. Although fully integrated approaches are available to register individual images to eliminate motion the impact on diagnostic accuracy has not been validated in patients [2].

\section{Materials and methods}

Cardiac stress and rest first pass perfusion images (SR prepared TFL, $160 \times 131$ matrix, $2.8 \times 2.3 \times 10 \mathrm{~mm}$ spatial resolution, TI $=100 \mathrm{~ms}$, TE $/ \mathrm{TR}=1.05 / 2.1 \mathrm{~ms}$, TGRAPPA factor 2) were acquired in eight patients with suspected ischemic heart disease on a clinical 1.5T scanner (MAGNETOM Avanto, Siemens Healthcare). Three short axis slices were acquired during infusion of $0.075 \mathrm{mMol} / \mathrm{kg}$ of Gadolinium (Magnevist, Bayer HealthCare Pharmaceuticals, USA) at rate of $4 \mathrm{ml} / \mathrm{sec}$. Using a conventional clinical protocol, patients were instructed to breath-hold during the beginning of the scan and resume shallow breathing after 30 hearts beats. Stress scans consisted of adenosine (Adenoscan, Astellas Pharma, USA) infusion $(0.14 \mathrm{mg} / \mathrm{kg} / \mathrm{min}$; rate: $0.2 \mathrm{cc} / \mathrm{sec} ; 4 \mathrm{~min})$. In addition to motion correction, inline processing also consisted of temporal filtering and surface coil correction [2].Conventional and motion-corrected images were assessed by 2 radiologists using the AHA 16-segment model and scored using a four point Likert scale (1-poor/nondiagnostic; to 4-excellent without artifacts) for each slice. Signal intensity curves in each segment from both methods were normalized by baseline signal intensity of the left ventricle.

\section{Results}

Eight patients were successfully scanned; perfusion defects were detected in 2 patients. The mean image quality score for motion corrected images $(3.76 \pm 0.34)$ was superior to conventional images $(2.59 \pm 0.46)$
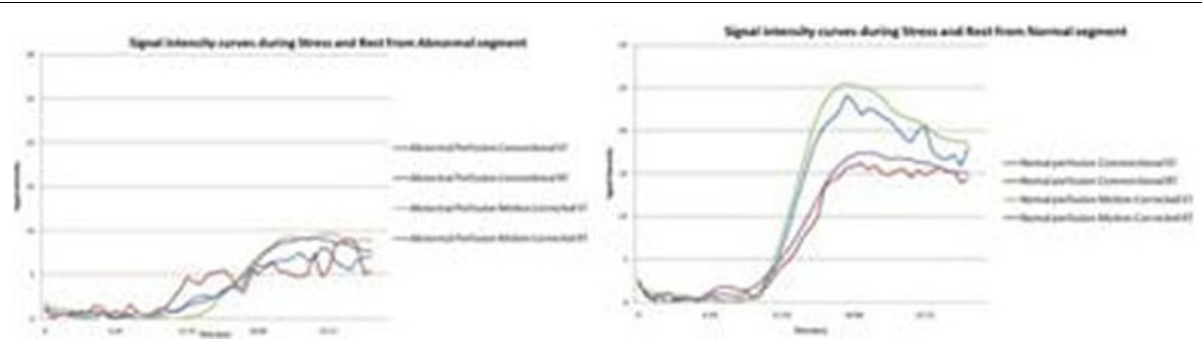

Figure 1 A) Time course for segment affected by surface coil correction (segment 5 AHA). B) Time course for segment less affected by this correction (segment AHA)

${ }^{1}$ Northwestern University, Chicago, IL, USA

Full list of author information is available at the end of the article

(c) 2011 Kino et al; licensee BioMed Central Ltd. This is an open access article distributed under the terms of the Creative Commons 
$(\mathrm{p}<0.0001)$.Stress and rest normalized signal intensity curves from segments with normal and reduced perfusion are similar for both techniques but some noticeable differences are evident (Figure 1).First, temporal filtering leads to reduced high frequency fluctuations, as expected. Second, inline surface coil correction results in higher signal after contrast arrives in the myocardium for some segments (Fig. 1A).

\section{Conclusions}

Clinical evaluation of motion corrected perfusion data shows significantly higher image quality. Future work will evaluate the efficacy of inline motion correction in the context of quantitative analysis.

\section{Author details}

${ }^{1}$ Northwestern University, Chicago, IL, USA. ${ }^{2}$ Siemens Healthcare, Chicago, IL, USA. ${ }^{3}$ Siemens Corporate Research, Princeton, NJ, USA.

Published: 2 February 2011

\section{References}

1. McNamara MT, et al: Radiology 1984.

2. Xue H, et al: Proc Intl Soc Mag Reson Med 2008, 16:4116.

doi:10.1186/1532-429X-13-S1-P54

Cite this article as: Kino et al:: Clinical evaluation of inline motion correction for cardiac perfusion MRI. Journal of Cardiovascular Magnetic Resonance 2011 13(Suppl 1):P54.
Submit your next manuscript to BioMed Central and take full advantage of:

- Convenient online submission

- Thorough peer review

- No space constraints or color figure charges

- Immediate publication on acceptance

- Inclusion in PubMed, CAS, Scopus and Google Scholar

- Research which is freely available for redistribution

Submit your manuscript at www.biomedcentral.com/submit 